\title{
The Blood Alcohol Concentration Testing Emergency Room Investigation Analysis Study: A 1-Year Review of Blood Alcohol Concentration Testing in an Emergency Department
}

\author{
Ayman Elgammal, ${ }^{1}$ Doireann Eves, ${ }^{2}$ Abbas Albaghli, ${ }^{2}$ Daniel Kane, ${ }^{2}$ Robert Durcan, \\ David Storey, ${ }^{2}$ and Peadar Gilligan ${ }^{1}$ \\ ${ }^{1}$ Department of Emergency Medicine, Beaumont Hospital, Dublin, Ireland \\ ${ }^{2}$ Royal College of Surgeons in Ireland, Dublin, Ireland \\ Correspondence should be addressed to Ayman Elgammal; draymanelgammal@hotmail.com
}

Received 16 August 2015; Accepted 21 October 2015

Academic Editor: Angelo P. Giardino

Copyright ( $) 2015$ Ayman Elgammal et al. This is an open access article distributed under the Creative Commons Attribution License, which permits unrestricted use, distribution, and reproduction in any medium, provided the original work is properly cited.

\begin{abstract}
Aim. To describe the actual use of blood alcohol concentration (BAC) testing in an emergency department. Method. This study was performed to examine in what circumstances emergency medicine doctors and nurses request blood alcohol concentrations and the outcome of patients so tested. A retrospective study was performed. A database of all the patients who presented to the emergency department and who were tested for BAC in 2012 was created. Descriptive statistics are used to present the findings. Results. During 2012, there were 1191 patients on whom BAC testing was performed. 37 patients had a BAC greater than the allegedly lethal concentration of $400 \mathrm{mg} / 100 \mathrm{~mL}$. Using a multifactorial analysis model, a higher blood alcohol concentration was associated with a lower Glasgow Coma Score. Conclusion. BAC testing is most often performed in the context of alleged overdose. BAC was performed in other clinical scenarios albeit in less than $2 \%$ of all ED attendances.
\end{abstract}

\section{Introduction}

Alcohol misuse is a major problem contributing to emergency department (ED) work load [1-3]. The dramatic increase in alcohol consumption in recent years and the associated burden on emergency departments have been well documented in Ireland $[1,2]$. It is estimated that one in four patients attending hospital emergency departments in Dublin area have an alcohol related diagnosis and one in eight patients $(13 \%)$ are clinically intoxicated at the time of their attendance [2].

Blood alcohol testing was introduced to the emergency department of the research hospital at the insistence of our colleagues in psychiatry who refused to assess patients with a blood alcohol concentration above 80 milligrams percent. A number of different units of measurement are used internationally. The measurement used in the hospital where the research was performed is milligrams of alcohol per 100 millilitres of blood [1]. A standard drink (bottle of beer or glass of wine) can increase a person's BAC by between $20 \mathrm{mg} /$ $100 \mathrm{~mL}$ and $40 \mathrm{mg} / 100 \mathrm{~mL}$ depending on their sex, weight, age, and so forth [4]. The road safety regulations in Ireland define the legal limit for driving as $50 \mathrm{mg}$ of alcohol per $100 \mathrm{~mL}$ of blood for experienced drivers and $20 \mathrm{mg} / 100 \mathrm{~mL}$ for inexperienced drivers [4].

This study was performed to see in what circumstances emergency medicine doctors and nurses requested blood alcohol concentrations and the outcome of patients so tested. It also examined blood alcohol concentration testing and variables such as Glasgow Coma Score (GCS), presenting complaint, patient outcome, age and gender of the patient, the time of day, and day of week when high BACs were most commonly detected.

\section{Methods}

This retrospective study was carried out in an emergency department (ED) with over 50,000 patient attendances 
annually in an 823-bed teaching hospital. Ethical approval was obtained from the Research and Ethics Committee. All emergency department patients who had a BAC measured in 2012 were included in the study. The Hospital Document Management System was used to access patient's charts and other scanned documents. Episode number, age, gender, date, day of the week, time of the day, presenting complaint, Glasgow Coma Scale Score, BAC $(\mathrm{mg} / 100 \mathrm{~mL})$, in overdose presence of paracetamol, tricyclic antidepressants, benzodiazepines, and aspirin, disposition (i.e., whether the patient was discharged, admitted, etc.), referral type if referred, and Intensive Care Unit (ICU) admission status were recorded. Exclusion criteria were patients under 16 years of age and patients with incomplete data.

Review of the emergency department notes did not reveal any fatalities in those who had undergone blood alcohol concentration testing for the year and so admission to ICU was used as an indicator of the severity of a patient's condition.

Descriptive statistics detailing means and standard deviations are presented for blood alcohol groups. A subsequent regression model measuring the association between GCS and BAC with other potential confounding variables was constructed. Stata 13 SE (College Station, Texas, USA) was used for the analysis. A $p$ value $<0.05$ was deemed to be significant.

\section{Results}

3.1. Population Analysis. During 2012, there were 1191 patients who had their BAC tested. Of these 706 (59\%) were male. A positive result was found in $626(52.6 \%)$ patients. Of those who tested positive, 388 (61.8\%) were male. The average BAC in those showing a positive result was $212 \mathrm{mg} / 100 \mathrm{Ml}$, that is, over four times the legal limit.

In the positive results group, 499 had a BAC less than $300 \mathrm{mg} / 100 \mathrm{~mL} .89$ patients had a BAC between 300 and $399 \mathrm{mg} / 100 \mathrm{~mL} .37$ patients (5.9\% of all positives) had a BAC equal to or greater than $400 \mathrm{mg} / 100 \mathrm{~mL}$ of whom $59.5 \%$ (22) were male.

The mean age of those testing positive for alcohol was 41.7 years whilst the mean age of those with a BAC over $400 \mathrm{mg} \%$ was 40.4 years.

3.2. Primary Measurement: BAC and Presenting Complaint. Table 1 shows the most common presentations resulting in a BAC test. The most common presenting complaint for which blood alcohol concentration was performed was deliberate self-poisoning. $61 \%$ of the patients tested had presenting complaints related to psychiatric conditions (deliberate self-poisoning, deliberate self-harm, depression, suicidal ideation/attempt, psychosis, or anxiety). There was a marginally higher percentage of negative BAC tests in the group with psychiatric complaints compared to the total patient group (50.6\% versus $45.1 \%$ ).

3.3. Secondary Measurement: BAC and the Burden on the Emergency Department. Approximately 2\% of emergency department patients had a BAC done in Beaumont Hospital ED. In the hospital where the research took place BAC testing is performed at the discretion of the treating doctor or triage
TABLE 1: Trends in presenting complaints of patients with a positive BAC result (numbers add up to greater than $100 \%$ as patients had more than one presenting complaint).

\begin{tabular}{lc}
\hline Presenting complaint & Percentage \\
\hline Deliberate self-poisoning (DSP) & $29.1 \%$ \\
Suicidal ideation/attempt & $14.8 \%$ \\
Deliberate self-harm (DSH) & $8.4 \%$ \\
Depression & $7.2 \%$ \\
Other psychiatric reasons & $1.6 \%$ \\
Collapse & $15.9 \%$ \\
Injury & $14.9 \%$ \\
Unwellness & $13.5 \%$ \\
Fall & $7.4 \%$ \\
Head/neck injury & $6.5 \%$ \\
Seizure & $6.1 \%$ \\
Other & $23 \%$ \\
\hline
\end{tabular}

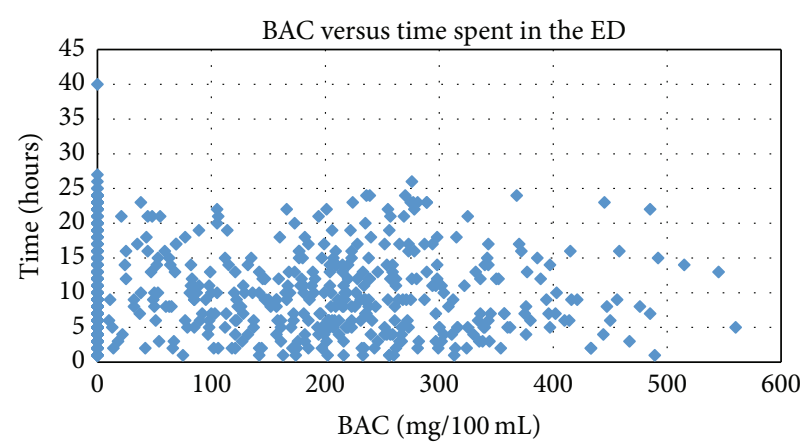

FIGURE 1: Time spent by each patient in the ED in relation to their BAC.

nurse. Alcohol dehydrogenase (an enzymatic method) is used to determine the $\mathrm{BAC}$ of a patient. The cost of this technique is just under $€ 1$ per test. $50.8 \%$ of patients with BAC measured were discharged. $17.1 \%$ were referred to community mental health services.

The time spent by each patient in the emergency department in relation to their BAC is shown in Figure 1.

The outcomes of patients with positive BACs are shown in Table 2 .

The greatest number of presentations with $\mathrm{BAC}<300 \mathrm{mg} /$ $100 \mathrm{~mL}$ was between Midnight and 8 a.m. The greatest number of presentations with BAC $>400 \mathrm{mg} / 100 \mathrm{~mL}$ was between 4 p.m. and Midnight. There were more positive BAC tests on the weekend days (38\% of all positives).

3.4. Tertiary Measurement: The Correlation between Blood Alcohol Concentration and Glasgow Coma Score. To examine the relationship between blood alcohol and Glasgow Coma Score (GCS), a multifactorial regression model was conducted to include age, sex, and drug use in determining outcome. Although the vast majority had a GCS of 15, there was a negative correlation between blood alcohol and GCS (higher blood alcohol concentrations had an inverse relationship to GCS score; $p<0.001$ ). Table 3 shows the relationship 
TABLE 2: Outcomes of patients with positive BACs.

\begin{tabular}{lcccc}
\hline & BAC $<300$ & BAC 300-349 & BAC 350-399 & 1 \\
Referred (12.6\%) & 73 & 3 & 9 & 2 \\
Left (16.5\%) & 73 & 13 & 15 & 8 \\
Discharged (50.8\%) & 255 & 29 & 6 & 19 \\
Admitted (18.8\%) & 93 & 11 & 0 & 8 \\
Admitted to ICU (1.3\%) & 6 & 2 & 0 \\
\hline
\end{tabular}

$0.6 \%$ were removed because they were disruptive and posing a danger to other patients and the ED staff. $12.6 \%$ were referred to a specialty team $(6 \%$ psychiatry referral, $27 \%$ of patients to medical team, and $14 \%$ to surgical team). $2 \%$ were transferred to other hospitals. $16.5 \%$ were left before treatment complete.

TABLE 3: Relationship between blood alcohol (BA) groups with age, gender, and GCS score.

\begin{tabular}{lccc}
\hline BAC & Mean age (SD) & \% male & Mean GCS (SD) \\
\hline 0 & $42.30(16.30)$ & 57 & $14.02(2.49)$ \\
$10-99$ & $41.02(15.37)$ & 57 & $14.56(1.62)$ \\
$100-199$ & $41.26(16.05)$ & 55 & $14.02(2.51)$ \\
$200-299$ & $42.89(16.46)$ & 64 & $13.83(2.36)$ \\
$300-399$ & $42.61(12.19)$ & 74 & $13.53(2.83)$ \\
$400-499$ & $42.45(10.45)$ & 63 & $12.65(3.50)$ \\
$500-599$ & $35.00(10.68)$ & 60 & $9.20(6.02)$ \\
\hline
\end{tabular}

between blood alcohol groups with age, gender, and GCS score.

3.5. Quaternary Measurement: Potentially Fatal Blood Alcohol Levels. 37 patients seen in the emergency department had a BAC greater than or equal to $400 \mathrm{mg} / 100 \mathrm{~mL}$, including 3 patients above $500 \mathrm{mg} / 100 \mathrm{~mL}$. No deaths or transfer to ICU was recorded in this group with blood alcohol levels in excess of eight times the legal limit.

\section{Discussion}

As with any investigation, requesting a BAC should be performed according to clinical judgment [5]. Touquet and Paton suggest that BAC should routinely be considered for all resuscitation room patients with collapse from alcohol/drugs, trauma, and intentional self-harm as well as for gastrointestinal bleeding and noncardiac chest pain [5]. Olson et al. suggest that BACs should be measured especially in the obtunded patient where no history can be given by the patient [6].

Some have argued that BAC, used with Glasgow Coma Scores, can affect patient management, for example, by helping to inform the decision about tracheal intubation or computed tomography scanning [7], especially for those with impaired consciousness, drug overdose, or trauma [810]. Indeed, it has been suggested that all comatose patients smelling of alcohol must have a BAC analysis [10].

In the research emergency department, BAC is often used to rule out alcohol ingestion, in patients attending with psychiatric conditions and requiring a psychiatric referral (61\%), rather than to determine the degree of intoxication of a patient. Patients with psychiatric conditions presenting to the emergency department should have a precise history, physical examination, and mental state examination which will help to rule out any other potential causes of the psychiatric symptoms and should guide the decision around BAC testing [11].

The peer reviewed literature gives differing perspectives on the usefulness of blood alcohol concentration testing and other investigations in those presenting with apparent psychiatric disorders. In a study by Hall et al. [12], $46 \%$ of the 100 patients admitted to a psychiatric facility had unrecognized medical illnesses and $80 \%$ of those needed treatment whilst Tintinalli and colleagues [13] found that, having reviewed 298 charts of emergency voluntary psychiatric admissions, only $4 \%$ of such patients had an acute medical condition that required intervention. Henneman and colleagues [14] found that $63 \%$ of patients with psychiatric symptoms were found on testing to have a medical cause for their symptoms whilst Olshaker and colleagues [15] discovered a medical aetiology in $<0.05 \%$ of patients with psychiatric complaints. Previous authors have found that history and physical examination had a sensitivity of $94 \%$ and $51 \%$, respectively, in identifying medical illness in patients with psychiatry related attendances [15]. Laboratory testing had a sensitivity of only $20 \%$ [15]. Korn et al. [16] concluded that patients with primary psychiatric complaints with other negative findings do not need ancillary testing in the emergency department.

The American Psychiatric Association (APA) recommends testing for the acute presentation [17]. In the American College of Emergency Physician (ACEP) guidelines, it is suggested that a patient's cognitive ability should be assessed rather than a blood alcohol level as blood alcohol concentrations do not correlate with the degree of intoxication [18].

$52.7 \%$ of the patients tested for blood alcohol concentration in our study had alcohol in their system. It was also observed that the average BAC in males was higher. These findings are in keeping with those of Woo et al. [19].

The finding of the inverse relationship of BAC to GCS is consistent with previous research suggesting that BACs of $200 \mathrm{mg}$ dL or higher have a greater impact on postinjury GCS Scores compared to lower levels of intoxication [20].

Previous research has suggested that the lethal BAC is over $400 \mathrm{mg} / 100 \mathrm{~mL}$ [21]. Studies have shown that the five most common presentations to the resuscitation room associated with a raised BAC are collapse, self-harm, trauma, gastrointestinal bleeding, and noncardiac chest pain [22]. Each of the above has an associated risk of death, but classification of alcohol as the primary cause of death in each is questionable. If a blood alcohol concentration is positive, it makes it possible that alcohol may have had a direct or indirect causal relationship to the patient's death [23]. The mechanism 
of death due to ethanol intoxication is generally considered to be suppression of the respiratory centre in the brain stem, with a concomitant lowered arterial oxygen saturation [24].

The results of our study raise questions as to the validity of considering alcohol levels greater than $400 \mathrm{mg} / 100 \mathrm{~mL}$ as a primary cause of death. The exact BAC considered to be fatal varies between authors with figures probably reflecting the personal experiences of the pathologists or toxicologists involved [25]. The difficulty in defining a universal lethal value arises for a number of reasons [23, 25]. Jones and Holmgren describe a pronounced tolerance to ethanol in patients attending hospital for detoxification. They also report that acute alcohol poisoning is most typically a complication of chronic alcoholism as an unaccustomed drinker usually does not reach lethal BAC [23].

In our study, blood alcohol concentration does not correlate with the time spent by each patient in the emergency department as seen in Figure 1. The correlation between the $\mathrm{BAC}$ and patients length of stay in emergency department has not been documented in the literature.

\section{Conclusion}

Blood alcohol concentration testing in the emergency department was performed in about $2 \%$ of ED patient attendances and was most frequently performed to assess patients' fitness to undergo psychiatric assessment. A higher blood alcohol concentration score is associated with a lower Glasgow Coma Score. Levels of alcohol in excess of $400 \mathrm{mg} \%$ were not found to result in death in the cohort in this study at or above that level.

\section{Conflict of Interests}

The authors declare that they have no conflict of interests regarding the publication of this paper.

\section{References}

[1] A. Hope, A. Gill, G. Costello, J. Sheehan, E. Brazil, and V. Reid, "Alcohol and injuries in the accident and emergency department: a national perspective," Drugnet Ireland, no. 17, pp. 4-5, 2006.

[2] O. O'Toole, C. Mahon, K. Lynch, and F. M. Brett, "Is the contribution of alcohol to fatal traumatic brain injuries being underestimated in the acute hospital setting?" Irish Medical Journal, vol. 102, no. 7, pp. 207-210, 2009.

[3] E. Csipke, R. Touquet, T. Patel et al., "Use of blood alcohol concentration in resuscitation room patients," Emergency Medicine Journal, vol. 24, no. 8, pp. 535-538, 2007.

[4] RSA, "The road safety authority_RSA in Ireland," http://www .rsa.ie/RSA/Licensed-Drivers/Driving-in-Ireland.

[5] R. Touquet and A. Paton, "Tackling alcohol misuse at the front line," British Medical Journal, vol. 333, no. 7567, pp. 510-511, 2006.

[6] K. N. Olson, S. W. Smith, J. S. Kloss, J. D. Ho, and F. S. Apple, "Relationship between blood alcohol concentration and observable symptoms of intoxication in patients presenting to an emergency department," Alcohol and Alcoholism, vol. 48, no. 4, pp. 386-389, 2013.
[7] G. J. Jurkovich, F. P. Rivara, J. G. Gurney, D. Seguin, C. L. Fligner, and M. Copass, "Effects of alcohol intoxication on the initial assessment of trauma patients," Annals of Emergency Medicine, vol. 21, no. 6, pp. 704-708, 1992.

[8] L. Weinberg and J. P. Wyatt, "Children presenting to hospital with acute alcohol intoxication," Emergency Medicine Journal, vol. 23, no. 10, pp. 774-776, 2006.

[9] American College of Surgeons, Advanced Trauma Life Support Program for Doctors, American College of Surgeons, Chicago, Ill, USA, 2006.

[10] G. Quaghebeur and P. Richards, "Comatose patients smelling of alcohol," British Medical Journal, vol. 299, no. 6696, article 410, 1989.

[11] F. N. Emembolu and L. S. Zun, "Medical clearance in the emergency department: is testing indicated?" Primary Psychiatry, vol. 17, no. 6, pp. 29-34, 2010.

[12] R. C. W. Hall, E. R. Gardner, M. K. Popkin, A. F. Lecann, and S. K. Stickney, "Unrecognized physical illness prompting psychiatric admission: a prospective study," American Journal of Psychiatry, vol. 138, no. 5, pp. 629-635, 1981.

[13] J. E. Tintinalli, F. W. Peacock, and M. A. Wright, "Emergency medical evaluation of psychiatric patients," Annals of Emergency Medicine, vol. 23, no. 4, pp. 859-862, 1994.

[14] P. L. Henneman, R. Mendoza, and R. J. Lewis, "Prospective evaluation of emergency department medical clearance," Annals of Emergency Medicine, vol. 24, no. 4, pp. 672-677, 1994.

[15] J. S. Olshaker, B. Browne, D. A. Jerrard, H. Prendergast, and T. O. Stair, "Medical clearance and screening of psychiatric patients in the emergency department," Academic Emergency Medicine, vol. 4, no. 2, pp. 124-128, 1997.

[16] C. S. Korn, G. W. Currier, and S. O. Henderson, "Medical clearance' of psychiatric patients without medical complaints in the Emergency Department," Journal of Emergency Medicine, vol. 18, no. 2, pp. 173-176, 2000.

[17] American Psychiatric Association, "Practice Guidelines," April 2010, http://www.psych.org/MainMenu/PsychiatricPractice/ PracticeGuidelines_l.aspx.

[18] American College of Emergency Physician, "Clinical Policy: Critical Issues in the Diagnosis and Management of the Adult Psychiatric Patient in the Emergency Department," http://www .acep.org/clinicalpolicies/?pg=2.

[19] S. H. Woo, W. J. Lee, W. J. Jeong, Y. Y. Kyong, and S. M. Choi, "Blood alcohol concentration and self-reported alcohol ingestion in acute poisoned patients who visited an emergency department," Scandinavian Journal of Trauma, Resuscitation and Emergency Medicine, vol. 21, no. 1, article 24, 2013.

[20] R. T. Lange, G. L. Iverson, J. R. Brubacher, and M. D. Franzen, "Effect of blood alcohol level on Glasgow Coma Scale scores following traumatic brain injury," Brain Injury, vol. 24, no. 7-8, pp. 919-927, 2010.

[21] K. Poikolainen, "Estimated lethal ethanol concentrations in relation to age, aspiration, and drugs," Alcoholism: Clinical and Experimental Research, vol. 8, no. 2, pp. 223-225, 1984.

[22] R. Touquet, E. Csipke, P. Holloway et al., "Resuscitation room blood alcohol concentrations: one-year cohort study," Emergency Medicine Journal, vol. 25, no. 11, pp. 752-756, 2008.

[23] A. W. Jones and P. Holmgren, "Comparison of blood ethanol concentration in deaths attributed to acute alcohol poisoning and chronic alcoholism," Journal of Forensic Sciences, vol. 48, no. 4, pp. 874-879, 2003. 
[24] B. Kringsholm, "Acute lethal alcohol intoxication (author's transl)," Zeitschrift für Rechtsmedizin, vol. 78, no. 4, pp. 313-319, 1976.

[25] R. A. Lahti and E. Vuori, "Fatal alcohol poisoning: medico legal practices and mortality statistics," Forensic Science International, vol. 126, no. 3, pp. 203-209, 2002. 


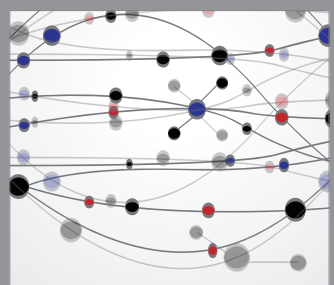

The Scientific World Journal
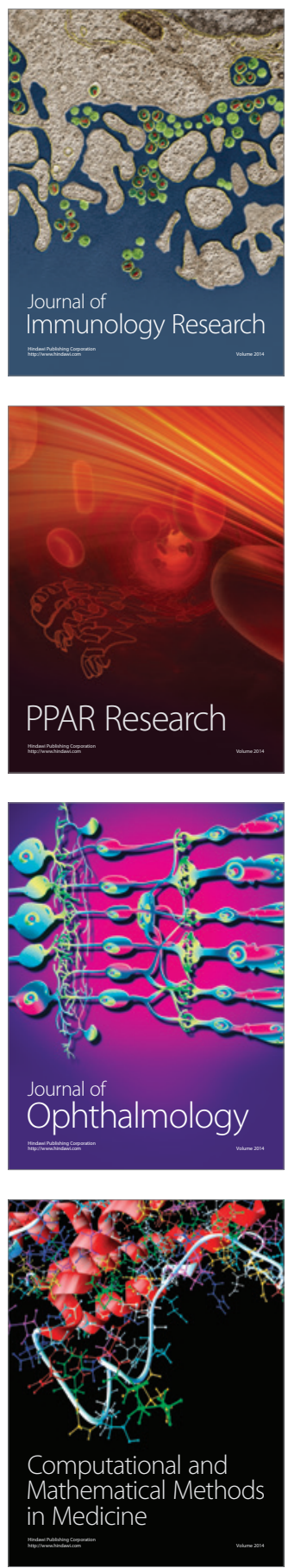

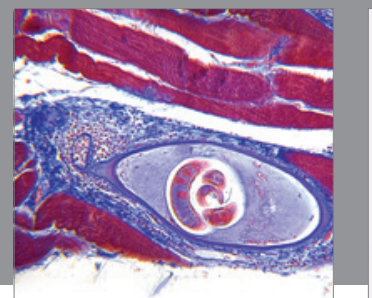

Gastroenterology

Research and Practice
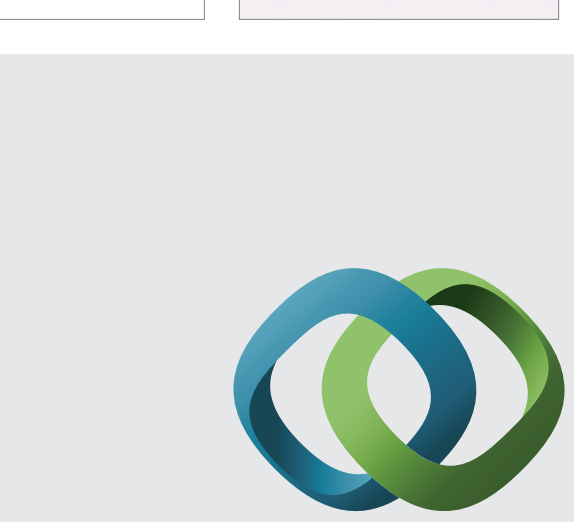

\section{Hindawi}

Submit your manuscripts at

http://www.hindawi.com
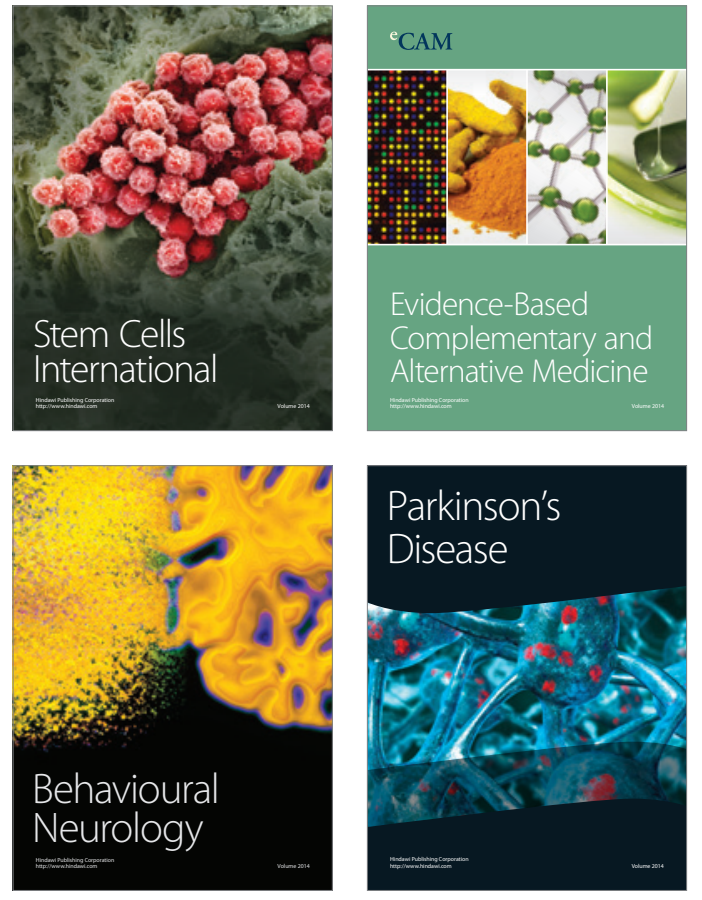
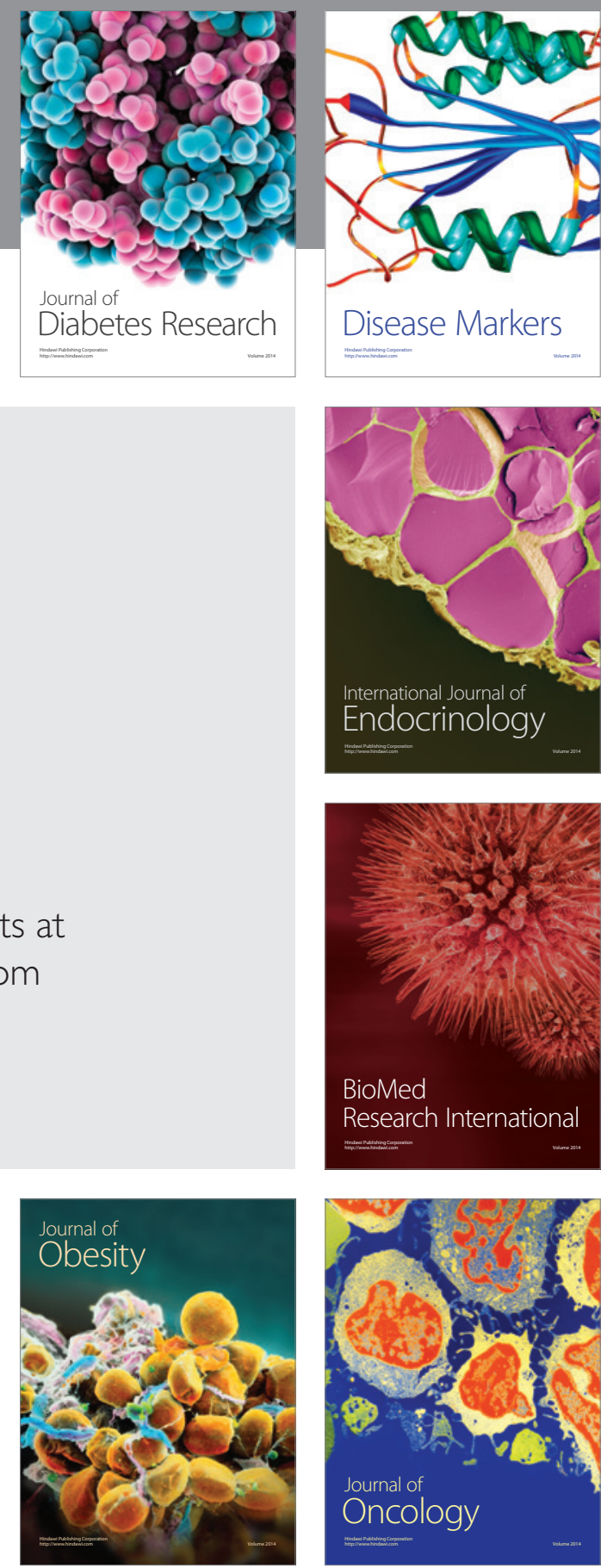

Disease Markers
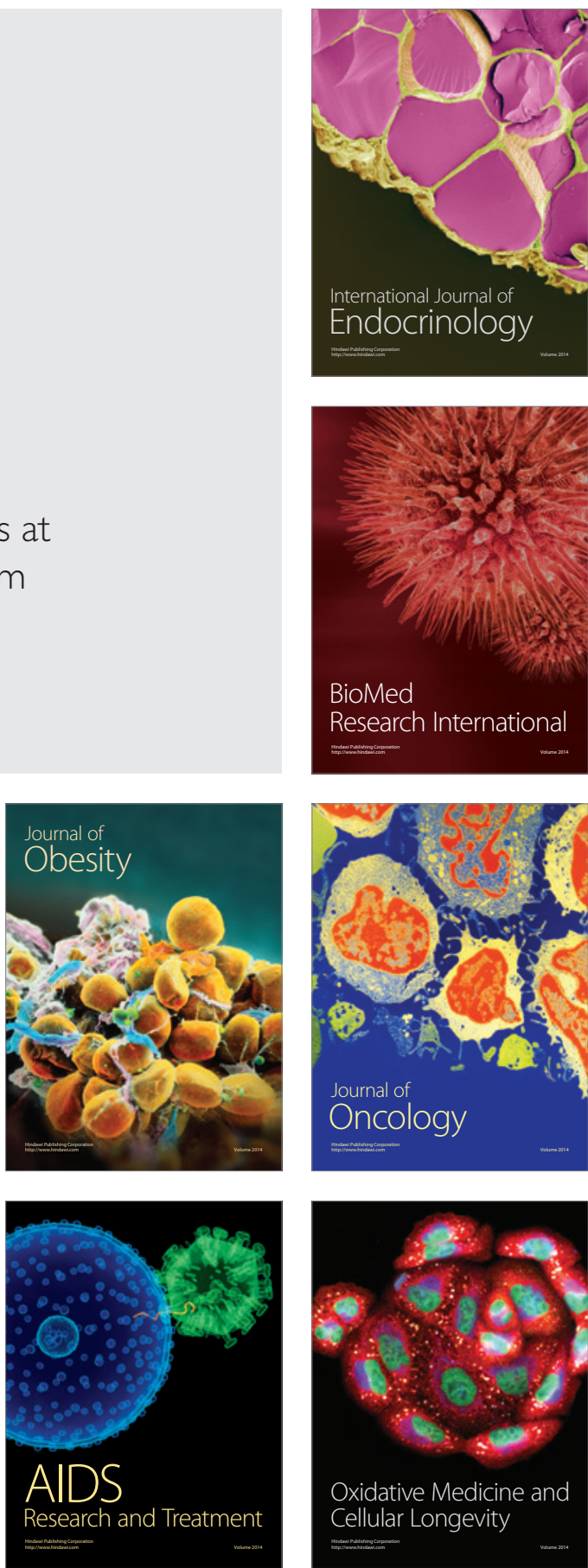